\title{
An analysis of the physiological strain of submaximal exercise in patients with chronic obstructive bronchitis
}

\author{
S . G . S P I R O, H. L. HA H N, R. H . T . E D W A R D S, \\ a n d N. B. P R I D E \\ Department of Medicine, Royal Postgraduate Medical School, Hammersmith Hospital, \\ Du Cane Road, London W12 OHS
}

\begin{abstract}
Spiro, S. G., Hahn, H. L., Edwards, R. H. T., and Pride, N. B. (1975). Thorax, 30, 415-425. An analysis of the physiological strain of submaximal exercise in patients with chronic obstructive bronchitis. An increasing work rate was performed by 40 patients with chronic obstructive bronchitis, split into two groups according to $\mathrm{FEV}_{1}$ (group $\mathrm{M}$, mean $\mathrm{FEV}_{1} 1.451$. and group $S$, mean $\mathrm{FEV}_{1} 0.62$ 1.), and by 20 normal, non-athletic men of similar age to the patients. Values for cardiac frequency and ventilation were interpolated to standard oxygen uptakes of $0.75,1.0$, and, where possible, $1.51 \mathrm{~min}^{-1}$. The tidal volume at a ventilation of 20 and 30 $1 \mathrm{~min}^{-1}$ was also determined.

The cardiac frequencies at oxygen uptakes of 0.75 and $1.01 \mathrm{~min}^{-1}$ were significantly higher in the patient groups than in the normal men, and were highest in patient group $\mathrm{S}$. The cardiac output when related to the oxygen uptake was in the normal range in all three groups of subjects, so that the patients had smaller stroke volumes than the normal men. Ventilation at oxygen uptakes of 0.75 and $1.01 \mathrm{~min}^{-1}$ was significantly higher in both patient groups than in the normal subjects; there were no significant differences between the two patient groups. Values for dead space/tidal volume ratio, alveolar-arterial oxygen gradient, and the percent venous admixture measured during a constant work rate test were significantly greater than normal in the patient groups.

Possible factors limiting exercise tolerance in these patients were assessed by extending the increasing work rate test from submaximum to maximum exercise. Changes in blood gas tensions and blood lactate concentrations from resting levels were small, and probably did not limit exercise performance. Measurements at maximum exercise did not add appreciably to the analysis of the disturbed cardiopulmonary function. This study has shown that major disturbances in cardiopulmonary function can be demonstrated without the need for stressing a patient to the limit of his effort tolerance.
\end{abstract}

\section{INTRODUCTION}

Although the working capacity of patients with chronic obstructive bronchitis has been studied by many authors, no simple way of comparing the capacity of these patients with that of normal subjects has been developed. Working capacity in normal subjects is assessed by measuring maximum oxygen uptake ( $\dot{V}_{2} \max$ ) (Robinson, 1938, Astrand, 1952; Astrand, I, 1960) but this requires several exercise tests carried to exhaustion and is obviously impractical, and possibly hazardous, in clinical practice. A simpler and less exhausting method is to predict $\dot{V}_{2}$ max from the relationship between cardiac frequency and oxygen consumption during progressive submaximal exercise by a linear ex- trapolation of oxygen consumption to a theoretical maximum cardiac frequency (Shephard et al., 1968). However, this prediction does not take into account the curvilinearity of the relation between cardiac frequency and oxygen consumption as maximum values are approached and tends to underestimate Vo2 max (Davies, 1968). Furthermore, the working capacity of patients with chronic obstructive bronchitis usually is limited by their impaired ventilatory capacity so that their cardiac frequencies on exercise do not approach the expected maximum values for their age (Armstrong et al., 1966; Gabriel, 1973). Recently, because of these difficulties in obtaining $\dot{V}_{2}$ max, Cotes et al. (1969) have suggested comparing measurements obtained during submaximal 
exercise at a standard oxygen uptake $\left(\dot{\mathrm{V}}_{2}\right)$. In normal populations they have used a $\dot{\mathrm{V}}_{2}$ of 1.5 $1 \mathrm{~min}^{-1}$. This $\dot{\mathrm{VO}}_{2}$ is too high for older women and for many patients; furthermore, values at a single $\dot{\mathrm{V}}_{2}$ provide no information on the evolution of the exercise response or of the overall capacity for exercise. For these reasons we have suggested an alternative approach in which measurements are made throughout an increasing work rate test and the results expressed, not only at suitable levels of $\dot{\mathrm{V}}_{2}$ $\left(0.75,1.0\right.$, and, where possible, $\left.1.51 \mathrm{~min}^{-1}\right)$, but also in terms of the slope of the relationship of cardiac frequency $(\mathrm{fH})$ and ventilation $(\dot{\mathrm{V}})$ with $\dot{\mathrm{V}}_{2}$. From these slopes and a knowledge of the maximum ventilation and heart rate a measure of 'physiological strain' can be obtained, which can be applied to both normal populations and patients (Spiro et al., 1974).

In this paper we describe the changes in cardiac frequency and in ventilation in 40 patients with chronic obstructive bronchitis and in 20 normal middle-aged men during a constant work rate exercise test. Some additional measurements of gas exchange and cardiac output were also made in all the subjects during a constant work rate test.

\section{SUBJECTS AND METHODS}

Forty men (aged 47 to 72 years) attending the Bronchitis Clinic at Hammersmith Hospital agreed to take part in the study. The criteria of chronic obstructive bronchitis were the same as those of Jones, Jones, and Edwards (1971). All the men had been cigarette smokers and 25 were still smoking at the time of the study. None gave a history of asthma or showed more than a $20 \%$ increase in the forced expiratory volume in 1 second $\left(\mathrm{FEV}_{1}\right)$ after bronchodilator. For analysis the patients were divided into two groups according to their $\mathrm{FEV}_{1}-$ a group $\mathbf{M}$, with moderate airways obstruction, mean $F E V_{1} 1.451$. (range 1.0-2.2 1.), and a group $S$ with severe airways obstruction, mean $\mathrm{FEV}_{1}$ 0.621 . (range $0.2-0.91$.). Bronchodilator therapy was omitted on the day of the study. All the subjects were in sinus rhythm and none was taking digoxin; two had a previous history of oedema and four had electrocardiographic evidence of right ventricular hypertrophy.

Twenty normal, sedentary, middle-aged men volunteered to take part in the study. A detailed medical history was taken on the day of the study. No subject had a history of abnormal exertional dyspnoea, angina or any other systemic illness. Dyspnoea grade was assessed as set out by the Medical Research Council (1965).

Height and weight were measured, and the lean body mass (LBM) calculated with the formulae of Durnin and Rahaman (1967) from the sum of fouro skinfold thicknesses measured over the tricepso and biceps muscles and in the subscapular and suprailiac regions. A resting venous blood samplep was taken from each subject for haemoglobin estimation. Vital capacity (VC) and $\mathrm{FEV}_{1}$ weres measured with a waterless bellows spirometero (McDermott, McDermott, and Collins, 1968) Three attempts were made and the highest value was recorded. Lung volumes and specific airways conductance were measured in the patients using a body plethysmograph (DuBois et al., 1956; DuBois? Botelho, and Comroe, 1956). The transfer factor for carbon monoxide (CO) was also measured in the patients using the single breath technique (Ogilvie et al., 1957), and expressed as the ratio of $\mathrm{CO}$ transfer per litre alveolar lung volume $\mathrm{STPD}_{\triangle}$ $\left(\mathrm{K}_{\mathrm{Co}}\right)$. The personal details of the subjects are summarized in Table I.

The subjects exercised while seated on an electric ally braked cycle ergometer (ELEMA). They first performed an increasing work rate test. After reaching a steady resting state, as judged by the continuous tracings of $\mathrm{fH}, \dot{\mathrm{V}}$, and mixed expired gas concentrations, exercise was begun at a powerō output of $100 \mathrm{kpm} \mathrm{min}^{-1}$ (16.7 watts) and increasecő by $100 \mathrm{kpm} \mathrm{min} \mathrm{m}^{-1}$ each minute. The patients were encouraged to continue for as long as possible, and in every case exercise was stopped because of 3 dyspnoea. The normal subjects were asked to stop, for safety reasons, when the cardiac frequencyọ. reached $85 \%$ of the maximum predicted for their age (Astrand, 1960). When it appeared that theo patients were approaching their maximum exercise capacity, blood samples were taken from a vaso-o dilated ear lobe (Godfrey, et al., 1971) for measure 3 . ment of oxygen tension $\left(\mathrm{PO}_{2}\right)$ and carbon dioxideo tension $\left(\mathrm{PCO}_{2}\right)$ during the last minute of exercise 3 In preliminary experiments we found no significanto differences in blood gas tensions in simultaneous samples taken from the brachial artery and ear lobe in 12 patients, so we have taken the blood gas tensions of capillary blood from the ear as equivalento to the tensions in arterial blood $\left(\mathrm{PaO}_{2}, \mathrm{PaCO}_{2}\right)^{\mathrm{N}} \mathrm{O}$ Measurement of blood gas tensions in 34 duplicate samples of ear lobe blood gave a coefficient of variation of $2.7 \%$ for $\mathrm{PaO}_{2}$ and $3.8 \%$ for $\mathrm{PaCO}_{2}$.

A further sample for blood lactate concentration was taken from the ear lobe 5 minutes after the end $\stackrel{5}{+}$ of exercise. Blood lactate concentration was mea-0 sured from five drops of blood collected into a tube? containing a weighed amount $(0.5 \mathrm{ml})$ of 0.86 mol $1^{-1}$ perchlorate solution. The tubes were shaken $\frac{\mathbb{Q}}{\square}$ and stored before being analysed by an enzymatico 
T A B LE I

PERSONAL DETAILS OF SUBJECTS (MEAN \pm SEM SHOWN)

\begin{tabular}{|c|c|c|c|}
\hline & \multirow{2}{*}{$\begin{array}{l}\text { Normal } \\
\text { Subjects }\end{array}$} & \multicolumn{2}{|c|}{ Patients } \\
\hline & & Group M & Group S \\
\hline$\underset{\mathrm{n}}{\mathrm{FEV}_{1} \text { (range, 1.) }}$ & $\begin{array}{c}2 \cdot 8-4 \cdot 7 \\
20\end{array}$ & $\begin{array}{c}1 \cdot 0-2 \cdot 2 \\
20\end{array}$ & $\begin{array}{c}0.2-0.9 \\
20\end{array}$ \\
\hline 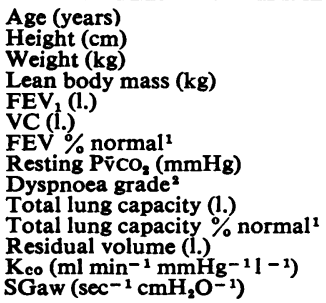 & $\begin{array}{r}54 \cdot 1 \pm 1 \cdot 1 \\
173.4 \pm 1 \cdot 5 \\
76.2 \pm 2.3 \\
62.3 \pm 1.6 \\
3.44 \pm 0.1 \\
4.48 \pm 0.1 \\
115.0 \pm 2.8\end{array}$ & $\begin{array}{c}60 \cdot 0 \pm 1 \cdot 0 \\
172 \cdot 8 \pm 1 \cdot 4 \\
72 \cdot 9 \pm 2 \cdot 8 \\
60 \cdot 2 \pm 1 \cdot 8 \\
1 \cdot 45 \pm 0 \cdot 1 \\
2 \cdot 92 \pm 0 \cdot 1 \\
49 \cdot 2 \pm 2 \cdot 9 \\
46 \cdot 2 \pm 1 \cdot 1 \\
2 \cdot 2 \pm 0 \cdot 2 \\
7 \cdot 58 \pm 0 \cdot 2 \\
123 \pm 5 \cdot 8 \\
4 \cdot 3 \pm 0 \cdot 2 \\
3 \cdot 71 \pm 0 \cdot 3 \\
0 \cdot 071 \pm 0.007\end{array}$ & $\begin{array}{l}62 \cdot 0 \pm 1 \cdot 7 \\
166 \cdot 4 \pm 1 \cdot 3 \\
68 \cdot 6 \pm 2 \cdot 9 \\
56 \cdot 6 \pm 2 \cdot 0 \\
0 \cdot 62 \pm 0 \cdot 1 \\
2 \cdot 01 \pm 0 \cdot 1 \\
24 \cdot 0 \pm 1 \cdot 7 \\
56 \cdot 6 \pm 1 \cdot 6 \\
3 \cdot 0 \pm 0.2 \\
7 \cdot 72 \pm 0 \cdot 4 \\
130 \pm 2 \cdot 7 \\
5 \cdot 2 \pm 0 \cdot 3 \\
3 \cdot 37 \pm 0 \cdot 3 \\
0 \cdot 043 \pm 0.006\end{array}$ \\
\hline
\end{tabular}

$\mathrm{K}_{\mathrm{co}}=$ transfer factor for carbon monoxide per unit of alveolar volume (STPD).

$\mathrm{SGaw}=$ specific airways conductance.

${ }^{1}$ Normal value predicted from age and height according to Cotes (1968).

${ }^{2}$ MRC instructions for the use of the questionnaire on respiratory symptoms, Medical Research Council (1965).

method (Hohorst, 1957). The coefficient of variation for 40 analyses of duplicate samples was $8.6 \%$ over the range of $0.5-4 \mathrm{mmol} \mathrm{1}^{-1}$ (mean 1.4 $\mathrm{mmol} \mathrm{l}^{-1}$ ).

Following a rest of at least 30 minutes the subjects performed a constant work rate test for 6 minutes. The power output selected for the patients was approximately $50 \%$ of the final work rate achieved during the progressive exercise test, and for the normal subjects was approximately $60 \%$ of their final work rate. Duplicate resting ear lobe blood samples were taken for measurement of $\mathrm{PaO}_{2}$, $\mathrm{PaCO}_{2}$, and blood lactate. Constant work rate exercise then began and during the sixth minute a further ear lobe sample was taken for blood gas tensions and lactate concentration. The mixed venous $\mathrm{CO}_{2}$ tension $\left(\mathrm{P}_{\bar{v}} \mathrm{CO}_{2}\right)$ was measured at rest and at the end of the sixth minute of exercise by the rebreathing method of Jones et al. (1967). Cardiac frequency, ventilation, and oxygen uptake were calculated from the Mingograf recordings in the resting period and at the end of each minute of exercise. The apparatus used, together with details of its accuracy, and the measurements made for the calculation of gas exchange have been described previously (Spiro et al., 1974).

The slope of the relationship of cardiac frequency and oxygen uptake ( $\mathrm{SfH})$ was measured from a 'least squares' regression line ( $\mathrm{fH}$ against $\dot{\mathrm{V}}_{2}$ ) automatically calculated and drawn by an Eliott 4100 digital computer. The slope for ventilation and oxygen uptake (SV) was drawn by eye through the linear (submaximal) range and did not include the inflexion that is often seen in normal subjects at high power outputs (Cotes, 1968). The slopes (SfH, SV) were expressed as the increases in $\mathrm{fH}$ or in $\dot{\mathrm{V}}$ required for an increase in $\dot{V}_{2}$ of $11 \mathrm{~min}^{-1}$. The range over which $\mathrm{fH}$ or $\dot{\mathrm{V}}$ could potentially be increased during exercise (that is, the difference between resting and maximum values) was taken as the 'adaptation capacity' (ACfH, ACV). Resting values for calculating $\mathrm{ACfH}$ and $\mathrm{ACV}$ were obtained from measurements made with the subject seated at rest on the cycle ergometer. In the normal subjects maximum ventilation was taken as the $\mathrm{FEV}_{1} \times 35$ (Gandevia and Hugh-Jones, 1957). In the patients, because of the relatively poor accuracy of existing predictions, the actual ventilation reached at the end of the exercise test was used. In all subjects the maximum heart rate was predicted from their age using the formula of Astrand (1960). By relating the absolute increase in ventilation or cardiac frequency (SV), $\mathrm{SfH}$ ) for a standard stress (an increase in $\mathrm{VO}_{2}$ of 1 $1 \mathrm{~min}^{-1}$ ) to an estimate of the individual's capacity to increase $\mathrm{fH}$ or $\dot{\mathrm{V}}$ (ACfH, ACV), the 'physiological strain' for ventilation or heart rate can be obtained (Spiro et al., 1974).

The pattern of breathing for each group was assessed by plotting ventilation against tidal volume after the method of Hey et al. (1966). The submaximal tidal volumes at a ventilation of 20 and $301 \mathrm{~min}^{-1}$ were interpolated from the individual plots.

The dead space/tidal volume ratio $\left(V_{D} / V_{T} \%\right)$ was calculated using the Bohr equation, from which the dead space $\left(V_{D}\right)$ was derived, allowing $60 \mathrm{ml}$ for the valve box dead space. Alveolar $\mathrm{Po}_{2}$ was derived with the alveolar air equation, and the measured $\mathrm{PaO}_{2}$ subtracted to obtain the alveolar-arterial $\mathrm{Po}_{2}$ gradient $\left(\mathrm{PA}_{\left.\mathrm{A}-\mathrm{aO}_{2}\right)}\right.$. The cardiac output (Q) was calculated by the indirect Fick equation for $\mathrm{CO}_{2}$, incorporating the 'downstream' correction (Jones et al., 1967). The percent venous admixture $\left(\hat{Q}_{\mathrm{S}} / \hat{Q}_{\mathrm{T}} \%\right)$ 
was estimated by use of the classical 'shunt' equation. Calculations were performed with the Eliott 4100 digital computer, using a programme based on the manipulation of the indirect Fick principle (Godfrey, 1970).

In the text and tables all gas volumes, except the $\mathrm{K}_{\mathrm{Co}}$, are given corrected to BTPS, and values for $\dot{\mathrm{V}}_{2}$ are corrected to STPD.

\section{RESULTS}

The two patient groups were on average 6 to 8 years older than the normal subjects. The patients in group $\mathbf{M}$ were smaller and lighter and had a lower lean body mass than the normal men (Table I); these anthropometric differences were only significant between group $S$ and the normal men $(t=2.05$; $0.025>P>0.01$ ). The dyspnoea grade (MRC, 1965) was significantly greater in patient group $S$ than in patient group $\mathrm{M}(t=2.63 ; 0.025>\mathrm{P}>0.01)$. The mean total lung capacity was above the predicted value in both patient groups but there was no significant difference between the two groups. The residual volume was significantly greater in patient group $S$ than in group $M(t=2.92 ; 0.01>\mathrm{P}>0.005)$. The transfer factor for $\mathrm{CO}$ related to alveolar volume $\left(\mathrm{K}_{\mathrm{Co}}\right)$ was considerably lower in the patient groups, than for normal middle-aged men (van Ganse Ferris, and Cotes, 1972). Specific airways conductance was significantly lower in patient group $\mathrm{S}$ than in patient group $\mathrm{M}(t=3.13 ; 0.005>\mathrm{P}>$ 0.001 ). These pulmonary function tests were not carried out on the normal men, but measurements of these variables in other normal subjects studied in this laboratory agree with published values (Cotes, 1968).

The interpolated responses of cardiac frequency at the submaximal levels of exercise $\left(\mathrm{fH} \mathrm{H}_{0.75}, \mathrm{fH}_{1.0}\right.$, $\mathrm{fH}_{1.5}$ ) are summarized in Table II and in Figure 1. Only two of the group $\mathrm{S}$ patients achieved an oxygen uptake of $1.51 \mathrm{~min}^{-1}$ and these data have not bee included. As half of the group $M$ subjects exceede $\Phi$ $1.51 \mathrm{VO}_{2} \mathrm{~min}^{-1}$, the mean value for this submaximat index was included. Only six subjects in group failed to reach an oxygen uptake of $1.01 \mathrm{~min}^{-} \mathrm{\Phi}$ The submaximal values for cardiac frequency were significantly higher in both the patient groups than the normal men at 0.75 and $1.01 \mathrm{~min}^{-1} \mathrm{VO}_{2}(t=3 \cdot 18$, $\mathrm{P}<0.001)$. The differences between the two patient groups did not reach statistical significance. The slope $(\mathrm{SfH})$ was similar for all three groups of subjects, but the ACfH was smaller in both the patient groups than in the normal men, as the patients were older and also had higher resting cardiac frequencies (Table II). However, the physio $\vec{F}$ logical strain index showed no significant difference between the three groups studied.

Ventilation at $0.75,1.0$, and $1.51 \mathrm{~min}^{-1} \dot{\mathrm{V}}_{2}$ wass higher in the patients than in the normal meen $(t=2.77 ; 0.01>\mathrm{P}>0.005)$, but there were no signifios cant differences in ventilation between group $\mathbf{M}$ and group S patients (Table III and Fig. 1). The slope of ventilation on oxygen uptake was slightly increasea (compared to the normal subjects) in the group patients $(t=2.03 ; 0.05>\mathrm{P}>0.025)$ but there was no significant change in the severely obstructe $\bar{f}$ patients.

The ACV was significantly smaller in patien group $M$ than in the normal subjects $\left(t=9 \cdot 1 \frac{*}{0}\right.$ $P<0.001)$ and smaller still in patient group $S$ tha in patient group $\mathrm{M}(t=4.9 ; \mathrm{P}<0.001)$. The physio logical strain index for ventilation was much greateọ. in both the patient groups than in the normal men and was significantly larger in patient group than in group $\mathrm{M}(t=2.82 ; 0.01>\mathrm{P}>0.005)$. The influence of differences of somatic muscle mass was corrected for by multiplying the physiologicat. strain index by the LBM. This did not cause an\$ significant change in physiological strain for $\dot{\mathrm{V}}$ o $\mathrm{fH}$ between any of the groups.

T A B L E I I

SUBMAXIMAL INDICES AND ESTIMATION OF ADAPTATION CAPACITY AND RELATED 'PHYSIOLOGICAL STRAIN' FOR CARDIAC FREQUENCY (MEAN \pm SEM SHOWN)

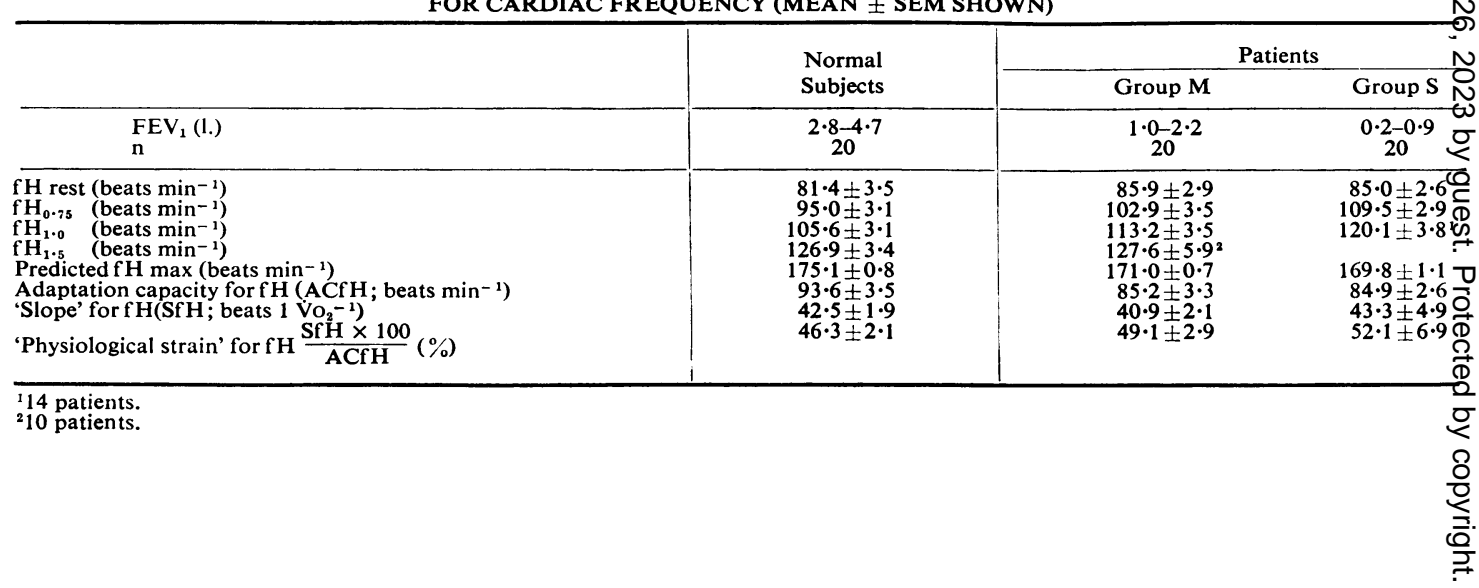


T A B L E I I I

SUBMAXIMAL INDICES AND ESTIMATIONS OF ADAPTATION CAPACITY AND RELATED 'PHYSIOLOGICAL STRAIN' FOR VENTILATION (MEAN \pm SEM SHOWN)

\begin{tabular}{|c|c|c|c|}
\hline & \multirow{2}{*}{$\begin{array}{l}\text { Normal } \\
\text { Subjects }\end{array}$} & \multicolumn{2}{|c|}{ Patients } \\
\hline & & Group M & Group S \\
\hline$\underset{\mathrm{n}}{\mathrm{FEV}_{\mathbf{1}}(1 .)}$ & $\begin{array}{c}2 \cdot 8-4 \cdot 7 \\
20\end{array}$ & $\underset{20}{1 \cdot 0-2 \cdot 2}$ & $\begin{array}{c}0.2-0.9 \\
20\end{array}$ \\
\hline 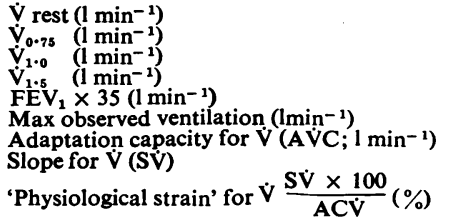 & $\begin{array}{r}13 \cdot 9 \pm 1 \cdot 3 \\
18 \cdot 7 \pm 1 \cdot 0 \\
25 \cdot 0 \pm 1 \cdot 0 \\
36 \cdot 6 \pm 1 \cdot 5 \\
121 \cdot 1 \pm 3 \cdot 9 \\
49 \cdot 4 \pm 2 \cdot 4 \\
108 \cdot 0 \pm 4 \cdot 1 \\
23 \cdot 8 \pm 1 \cdot 4 \\
22 \cdot 5 \pm 1 \cdot 4\end{array}$ & $\begin{array}{l}13 \cdot 8 \pm 1 \cdot 0 \\
24 \cdot 4 \pm 1 \cdot 1 \\
32 \cdot 0 \pm 1 \cdot 4 \\
43 \cdot 3 \pm 2 \cdot 4^{2} \\
50 \cdot 8 \pm 2 \cdot 9 \\
48 \cdot 6 \pm 2 \cdot 1 \\
34 \cdot 8 \pm 2 \cdot 6^{3} \\
31 \cdot 5 \pm 1 \cdot 8 \\
97 \cdot 2 \pm 7 \cdot 50^{2}\end{array}$ & $\begin{array}{l}11 \cdot 4 \pm 0 \cdot 5 \\
23 \cdot 0 \pm 0 \cdot 9 \\
29 \cdot 5 \pm 1 \cdot 2^{1} \\
21 \cdot 9 \pm 1 \cdot 6 \\
30 \cdot 0 \pm 2 \cdot 1 \\
19 \cdot 0 \pm 1 \cdot 9^{2} \\
25 \cdot 6 \pm 1 \cdot 4 \\
152 \cdot 7 \pm 18 \cdot 7^{2}\end{array}$ \\
\hline
\end{tabular}

14 patients.

210 patients.

Adaptation capacity and physiological strain in patient groups calculated from the maximum observed ventilation.
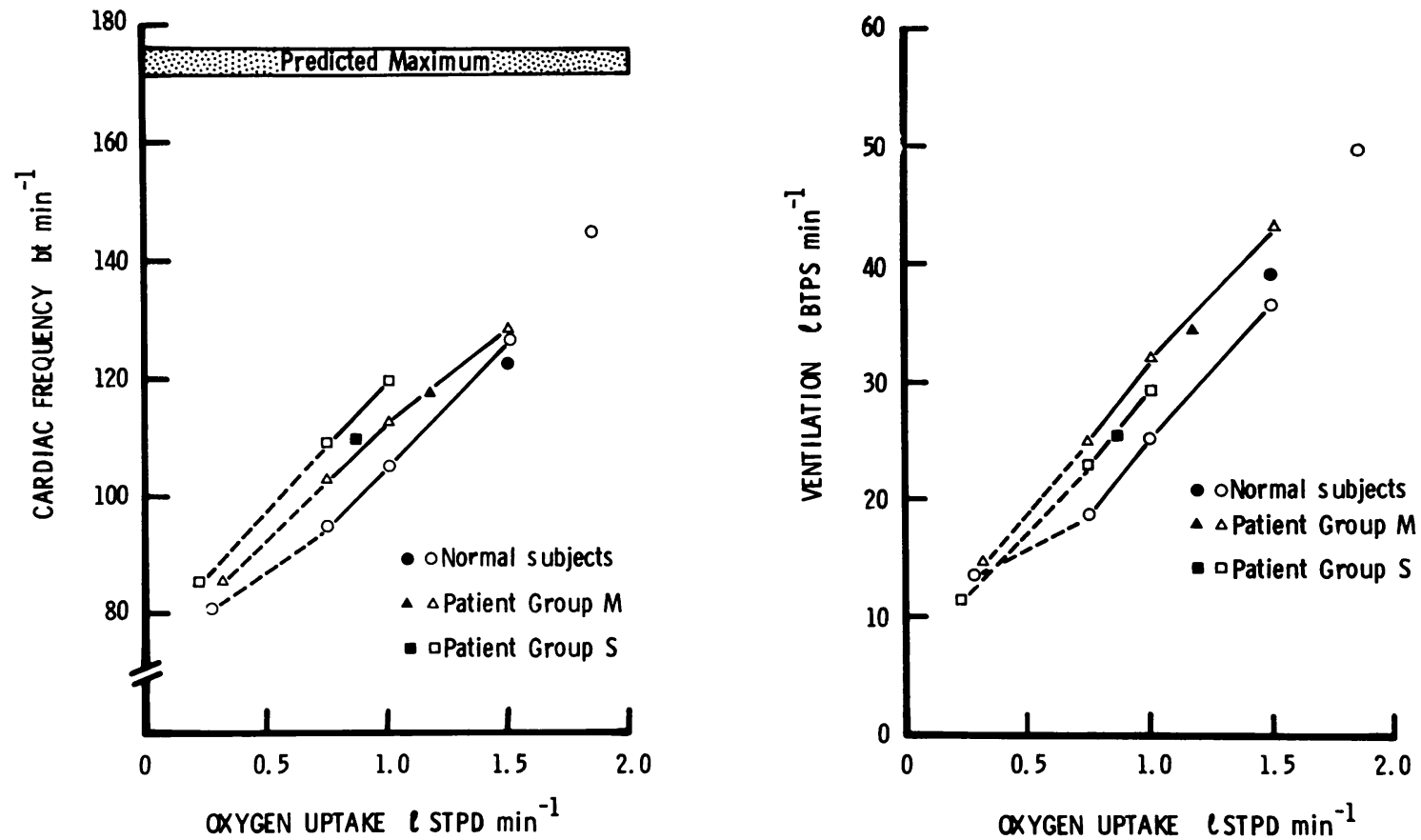

Fig. 1. Mean values for cardiac frequency and ventilation at rest and at the submaximal levels of $\dot{V} \mathrm{O}_{2}(0 \cdot 75,1 \cdot 0$, and $1.5 \mathrm{l} \mathrm{min}^{-1}$ ) for all three groups of subjects (open symbols). The values during the last minute of constant work rate exercise (closed symbols) are also shown. The submaximal indices for cardiac frequency are higher in the patient groups than in the normal subjects and are higher in patient group $S$ than group $M$. There is no increase in the submaximal ventilatory indices in group $S$ from group $M$.

Plots of $V_{T}$ against $\dot{V}$ (Hey et al., 1966) for 24 of the patients and for half of the normal men who were selected at random are summarized in Figure $2 \mathrm{a}$. Of the other 16 patients, four showed no increase in $V_{T}$ but only in frequency during exercise, and 12 were unable to achieve a ventilation of $301 \mathrm{~min}^{-1}$.
The mean values of $V_{\text {T20 }}$ and $V_{\text {T30 }}$ were significantly smaller in both the patient groups than in the normal men $(t=3.5 ; \mathrm{P}<0.001)$ as were the maximum tidal volumes recorded $\left(V_{\mathrm{T}} \max \right)(t=4.4 ; \mathrm{P}<0.001)$. When the tidal volumes were expressed as a percentage of the VC, the submaximal and maximal tidal volume 


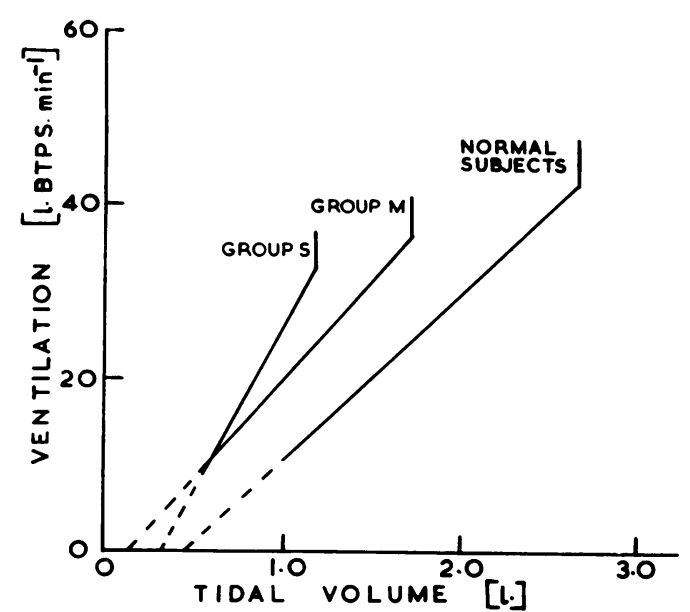

FIG. 2(a). Mean relationships of exercise tidal volume and ventilation illustrating the patterns in the two patient groups and the normal subjects. The maximum tidal volumes reached are indicated by the inflexions.

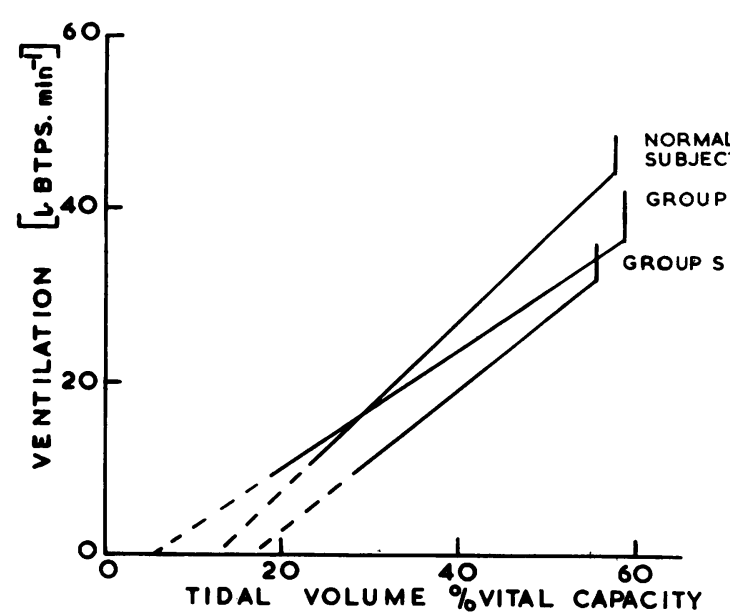

(b). Mean relationships between the tidal volume as percentage of the vital capacity, and ventilation.

T A B L E I V

MEASUREMENTS DURING LAST MINUTE OF INCREASING WORK RATE TEST (MEAN \pm SEM SHOWN)

\begin{tabular}{|c|c|c|c|}
\hline & \multirow{2}{*}{$\begin{array}{l}\text { Normal } \\
\text { Subjects }\end{array}$} & \multicolumn{2}{|c|}{ Patients } \\
\hline & & Group M & Group S \\
\hline$\underset{\mathrm{n}}{\mathrm{FEV}_{1}(1 .)}$ & $\begin{array}{c}2 \cdot 8-4 \cdot 7 \\
20\end{array}$ & $\frac{1 \cdot 0-2 \cdot 2}{20}$ & $\begin{array}{c}0.2-0.9 \\
20\end{array}$ \\
\hline 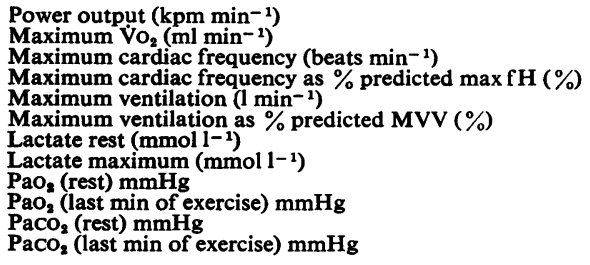 & $\begin{array}{l}900 \pm 54 \cdot 7 \\
2012 \pm 104 \\
152 \cdot 4 \pm 2 \cdot 6 \\
86 \cdot 7 \pm 1 \cdot 9 \\
54 \cdot 4 \pm 2 \cdot 6 \\
45 \cdot 5 \pm 2 \cdot 1 \\
= \\
91 \cdot \overline{5} \pm 1 \cdot 7 \\
37 \cdot \overline{6} \pm 1 \cdot 1\end{array}$ & $\begin{array}{l}595 \pm 32 \cdot 8 \\
1511 \pm 83 \\
140 \cdot 0 \pm 4 \cdot 2 \\
82 \cdot 0 \pm 2 \cdot 4 \\
48 \cdot 6 \pm 2 \cdot 1 \\
99 \cdot 0 \pm 4 \cdot 7 \\
0 \cdot 80 \pm 0 \cdot 1 \\
3 \cdot 63 \pm 0 \cdot 3 \\
76 \cdot 3 \pm 2 \cdot 1 \\
76 \cdot 2 \pm 3 \cdot 0 \\
36 \cdot 5 \pm 0 \cdot 8 \\
41 \cdot 0 \pm 1 \cdot 3\end{array}$ & $\begin{array}{r}385 \pm 33 \cdot 5 \\
1034 \pm 85 \\
120 \cdot 9 \pm 3 \cdot 6 \\
71 \cdot 0 \pm 1 \cdot 9 \\
30 \cdot 0 \pm 2 \cdot 1 \\
146 \cdot 0 \pm 10 \cdot 6 \\
0 \cdot 82 \pm 0 \cdot 1 \\
2 \cdot 56 \pm 0 \cdot 2 \\
69 \cdot 7 \pm 1 \cdot 4 \\
60 \cdot 9 \pm 2 \cdot 3 \\
44 \cdot 6 \pm 1 \cdot 5 \\
49 \cdot 0 \pm 1 \cdot 8\end{array}$ \\
\hline
\end{tabular}

measurements became similar in all three groups (Fig. 2b). Complete details of the mean and individual data are available elsewhere (Spiro, 1975).

The slope (m) of each Hey plot was similar in group $M$ and the normal subjects but was significantly steeper in group $S(t=2 \cdot 15 ; 0.05>\mathrm{P}>0.025)$. The intercept (k) was similar in all three groups.

Data relating to the last minute of the increasing work rate test are summarized in Table IV. The blood lactate concentration after exercise was significantly higher in group $\mathbf{M}$ than in group $\mathbf{S}$ $(t=2.71 ; \mathrm{P}<0.01)$. The resting $\mathrm{PaO}_{2}$ was significantly lower in patient group $M$ than in the normal subjects $(t=7.1 ; \mathrm{P}<0.001)$ and was significantly lower in group $S$ than in group $M(t=2.28 ; 0.05>P$ $>0.025)$. The resting $\mathrm{PaCO}_{2}$ was significantly raised in group $S$ from that in the normal subjects $(t=4 \cdot 24$;
$\mathbf{P}<0.001$ ). In the last minute of exercise, a significant ${ }^{3}$ fall in $\mathrm{PaO}_{2}$ had occurred only in patient group $\mathrm{S}$ 윽 $(t=2.97 ; 0.005>\mathrm{P}>0.001)$. The $\mathrm{PaCO}_{2}$ showed as slight increase in both patient groups which was not을. significant.

The resting $\mathrm{PaO}_{2}$ was found to correlate well with ${ }^{\circ}$ the FEV $1(r=0.78 ; P<0.001 ;$ Fig. 3$)$. The maximum $\sim$ ventilation reached during the last minute of exercise ${ }_{\omega}^{N}$ was significantly correlated with the measuredo $\dot{\mathrm{VO}}_{2} \max (\mathrm{r}=0.85 ; \mathrm{P}<0.001)$ and there was also ao significant relationship between $F E V_{1}$ and the measured $\dot{\mathrm{Vo}}_{2}$ max in the patients $(\mathrm{r}=0.70 ; \mathrm{P}<0.001 ; \stackrel{+}{+}$ Fig. 4).

Data obtained in the constant work rate test are summarized in Table V. All subjects exercised in $\vec{\Omega}$ approximately the middle of their working capacity. $\mathbb{\mathbb { D }}$ The $V_{D} / V_{T} \%, V_{D}, A-a P_{2}$ gradient, and $\mathbf{Q}_{S} / Q_{T} \%$ 


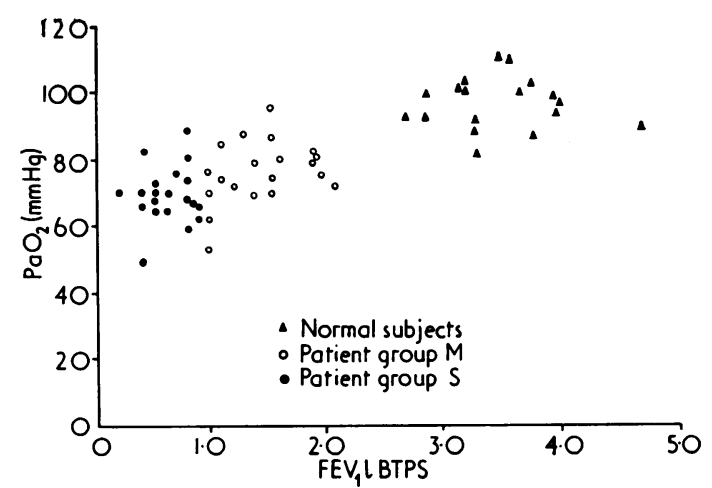

FIG. 3. Relationship between the resting $\mathrm{PaO}_{2}$ and the $F E V_{1}$ for the two patient groups and the normal subjects.

were all significantly larger in both the patient groups than in the normal men $(t=4.0 ; \mathrm{P}<0.001)$. The alveolar-arterial $\mathrm{Po}_{2}$ gradient was greater in group $\mathbf{S}$ than in group $\mathbf{M}$, and the increase in $\mathrm{V}_{\mathrm{D}} /$ $\mathrm{V}_{\mathrm{T}} \%$ and $\mathbf{Q}_{\mathrm{S}} / \mathbf{Q}_{\mathrm{T}} \%$ in group $\mathrm{S}$ reached statistical significance over group $\mathrm{M}(t=2.9 ; 0.01>\mathrm{P}>0.005)$.

The relationship of cardiac output (Q) to $\dot{V}_{2}$ for all three groups fell within the ranges previously reported for normal middle-aged subjects (Reeves et al., 1961; Granath, Jonsson and Strandell, 1964; Becklake et al., 1965; Higgs et al., 1967). The stroke volume (SV) was greatest in the normal men, but this differed significantly only from patient group $S$ $(t=3.29 ; 0.005>\mathrm{P}>0.001)$.

\section{DISCUSSION}

These results confirm previous studies in showing that the major limitation to exercise was the impaired ventilatory capacity; as a result both maximum $\mathrm{O}_{2}$ uptake and the maximum cardiac frequency achieved on exercise were often greatly reduced. Hence it is not possible to use comparative data obtained in normal populations at a $\dot{V}_{2}$ of 1.51 $\min ^{-1}$ (Davies, 1972) and even comparisons at a

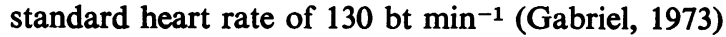
may be impossible in more severely affected patients. Detailed submaximal indices at lower levels of $\dot{\mathrm{VO}}_{2}$ are therefore essential in order to allow direct comparison between patient and normal populations.

CIRCULATORY RESPONSE TO EXERCISE Cardiac output was normal, but the heart rate was abnormally high on exercise in both patient groups $\mathbf{S}$ and $\mathbf{M}$. Heart rate in group $\mathbf{S}$ was higher than in group $\mathbf{M}$; those patients in group $\mathbf{M}$ who achieved a $\dot{\mathrm{V}}_{2}$ in excess of $1.51 \mathrm{~min}^{-1}$ had a normal response. The similar

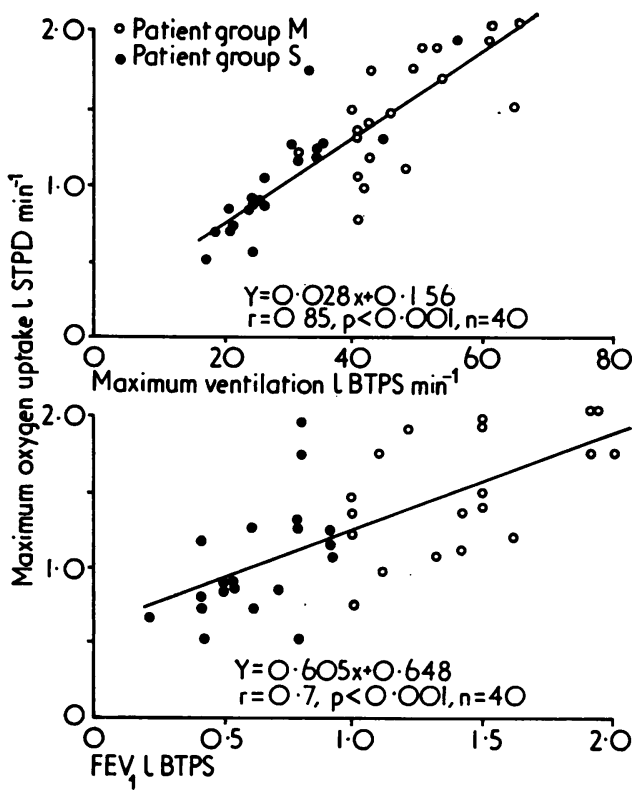

FIG. 4. Rel:tionship between the maximum oxygen uptake measured during the last minute of the increasing work rate test in the two patient groups and the maximum exercise ventilation achieved (above) and the FEV (below).

T A B L E V

MEASUREMENTS DURING SIXTH MINUTE OF CONSTANT WORK RATE EXERCISE (MEAN \pm SEM SHOWN)

\begin{tabular}{|c|c|c|c|}
\hline & \multirow{2}{*}{$\begin{array}{l}\text { Normal } \\
\text { Subjects }\end{array}$} & \multicolumn{2}{|c|}{ Patients } \\
\hline & & Group $\mathbf{M}$ & Group S \\
\hline${\underset{n}{n}}_{\text {FEV }}(1)$. & $\begin{array}{c}2 \cdot 8-4 \cdot 7 \\
20\end{array}$ & $\frac{1 \cdot 0-2 \cdot 2}{20}$ & $\begin{array}{c}0.2-0.9 \\
20\end{array}$ \\
\hline $\begin{array}{l}\text { Oxygen uptake }\left(\mathrm{ml} \mathrm{min}^{-1}\right) \\
\text { Cardiac frequency }\left(\mathrm{bt} \mathrm{min}^{-1}\right) \\
\text { Cardiac output }\left(1 \mathrm{~min}^{-1}\right) \\
\text { Stroke volume }\left(\mathrm{ml}^{-1}\right) \\
\text { A-aro, gradient }\left(\mathrm{mmHg}^{-}\right) \\
\text {Ventilation }\left(1 \mathrm{~min}^{-1}\right) \\
\text { VD / VT }(\%) \\
\text { VD (ml) } \\
\text { Venous admixture (\%) }\end{array}$ & $\begin{aligned} 1502 & \pm 41 \\
123 \cdot 2 & \pm 3 \cdot 0 \\
14 \cdot 9 & \pm 0 \cdot 7 \\
122 \cdot 4 & \pm 7 \cdot 1 \\
19 \cdot 8 & \pm 2 \cdot 3 \\
39 \cdot 1 & \pm 1 \cdot 9 \\
16 \cdot 1 & \pm 1 \cdot 4 \\
264 & \pm 20 \\
2 \cdot 8 & \pm 0 \cdot 4\end{aligned}$ & $\begin{array}{c}1172 \pm 59 \\
117 \cdot 6 \pm 3 \cdot 5 \\
12 \cdot 4 \pm 0 \cdot 7 \\
105 \cdot 9 \pm 6 \cdot 5 \\
28 \cdot 8 \pm 2 \cdot 4 \\
33 \cdot 6 \pm 2 \cdot 2 \\
31 \cdot 6 \pm 2 \cdot 1 \\
409 \pm 34 \\
7 \cdot 2 \pm 1 \cdot 9\end{array}$ & $\begin{array}{r}864 \pm 60 \\
109 \cdot 0 \pm 3 \cdot 2 \\
9 \cdot 8 \pm 0 \cdot 7 \\
94 \cdot 2 \pm 4 \cdot 8 \\
34 \cdot 4 \pm 1 \cdot 4 \\
25 \cdot 3 \pm 1 \cdot 5 \\
42 \cdot 5 \pm 2 \cdot 3 \\
319 \pm 16 \\
14 \cdot 5 \pm 1 \cdot 6\end{array}$ \\
\hline
\end{tabular}


slope ( $\mathrm{SfH})$ in all three groups indicated that the patients, despite a high resting cardiac frequency, had their greatest increase at the start of exercise (Fig. 1). While normal subjects commencing seated exercise increase their stroke volume by approximately $30 \%$ (Astrand and Rodahl, 1970), Gabriel (1973) measured only an $8 \%$ increase in SV in a group of subjects with chronic obstructive bronchitis and a mean $\mathrm{FEV}_{1}$ similar to that of patient group $\mathbf{M}$. Marcus et al. (1970) also found a low SV with no change on exercise and a normal cardiac output in patients with chronic airways obstruction. Whether the impaired SV response is due to raised pulmonary artery pressure (Gabriel, 1973) or to features of left ventricular dysfunction (Baum et al., 1971) is uncertain.

VENTILATORY RESPONSE TO EXERCISE Ventilation at a given oxygen uptake was greater in both patient groups than in the normal subjects. This enabled the less severely affected patients (group $\mathbf{M}$ ) to maintain an arterial $\mathrm{PaCO}_{2}$ within normal limits despite the increased dead space. However, there was no tendency for the more severely affected patients (group $S$ ) to show larger increases in ventilation than group $M$ patients even though they had more severe abnormalities in $\mathrm{V}_{\mathrm{D}} / \mathrm{V}_{\mathrm{T}} \%$ and in other indices of pulmonary gas exchange such as A-aPO gradient, venous admixture (Table $\mathrm{V}$ ), and $\mathrm{K}_{\mathrm{co}}$. We presume that patients with airflow obstruction initially try to keep $\mathrm{PaCO}_{2}$ normal during exercise by augmenting their ventilation on exercise but that as obstruction progresses this compensation becomes uneconomic and $\mathrm{PaCO}_{2}$ rises. Nevertheless the deterioration in blood gases during exercise was still remarkably small considering the severity of the airways obstruction. The patients tended to have smaller tidal volumes during exercise, but, when related to $\mathrm{VC}$, their maximum tidal volume incorporated approximately $50 \%$ of the VC. The overall pattern became similar to that of the normal men and to normal subjects performing voluntary hyperventilation (Freedman, 1970) and breathing $\mathrm{CO}_{2}$ (Hey et al., 1966). The intercept ' $k$ ' was considered to be 'related to the respiratory dead space' by Hey el al. (1966). There was, however, no significant difference between any of the patient groups and the normal subjects for ' $k$ ', although dead spaces and $\mathrm{V}_{\mathrm{D}} / \mathrm{V}_{\mathrm{T}}$ ratios were higher in both patient groups. Thus the possible significance of ' $k$ ' remains obscure.

It was the purpose of this study to introduce new indices for assessing the cardiorespiratory responses to submaximal exercise. Indices at submaximal oxygen uptakes, well within the range of capability of patients, can readily be compared with those reported for normal subjects (Spiro et al., 1974 $\overrightarrow{\overrightarrow{\hat{P}_{0}}}$ The slopes (SfH, SV) indicate how much these variables will increase in the course of everyda activities requiring an increase in energy expenditur equivalent to $11 \mathrm{~min}^{-1} \dot{\mathrm{V}}_{2}$. The physiologicat strain, however, depends on the overall physicas capacity of the individual to exercise, and in turfp requires accurate knowledge of maximum values of $\mathrm{fH}$ and $\dot{\mathrm{V}}$. $\mathrm{fH}$ max can be estimated from the age according to the well established formula of Astrang (1960) - for details see Spiro et al. (1974).

The prediction of maximum exercise ventilation is difficult, especially in patients with severe airways obstruction. Clark et al. (1969) showed that althougit the ventilatory capacity could be predicted from the $\mathrm{FEV}_{1}$, this was subject to considerable variations In the present study the opportunity was taken to re-examine the relation of $\mathrm{FEV}_{1}$ and exercise ventilatory capacity. The relationship obtained if this part of the study agreed with that taken frort the data of Raimondi et al. (1970) and Jones et at. (1971). By combining all three studies (performes in the same laboratory), it has been possible to have a more confident assessment of maximum exercise

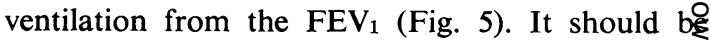
noted that the prediction of maximum exercise ventilation as $\mathrm{FEV}_{1} \times 35$, though adequate if normal subjects, considerably underestimates the exercise ventilation achieved by patients with a FEV $_{1}<1.01$.

CHANGES SEEN AT MAXIMUM EXERCISE The resting $\mathrm{PaO}_{2}$ in the middle-aged normal subjects was simila to those of other studies (Mellemgaard, 1966; Harrs et al., 1974). The resting $\mathrm{PaO}_{2}$ was lower in oự patients than in patients with milder bronchits studied elsewhere (Levine et al., 1970) but, wheñ matched for $F E V_{1}$, the values for group $M$ lay close to values reported in other studies (Simonssor? Malmberg, and Berglund, 1969; Gabriel, 1973f There was a significant drop in $\mathrm{PaO}_{2}$ from rest to maximal exercise only in patient group $S$ (Tabl IV), and this was similar to that found by Gabridb (1973) in his patients with chronic obstructive bronchitis. It seems unlikely that this fall in Paoes was large enough to influence the end point of the exercise test. There was no correlation between the size of the fall in $\mathrm{PaO}_{2}$ on exercise and the pulmonaro transfer factor for $\mathrm{CO}\left(\mathrm{K}_{\mathrm{CO}}\right)$.

The peak rise in blood lactate concentration, measured 5 to 10 minutes after maximal exercisw (Astrand, 1960), was much smaller than that foun $\bar{\Phi}$ in normal subjects (Robinson, 1938; Astrand, 1958 Strandell, 1964). None of the patients showed th disproportionate increase in ventilation as maximung 


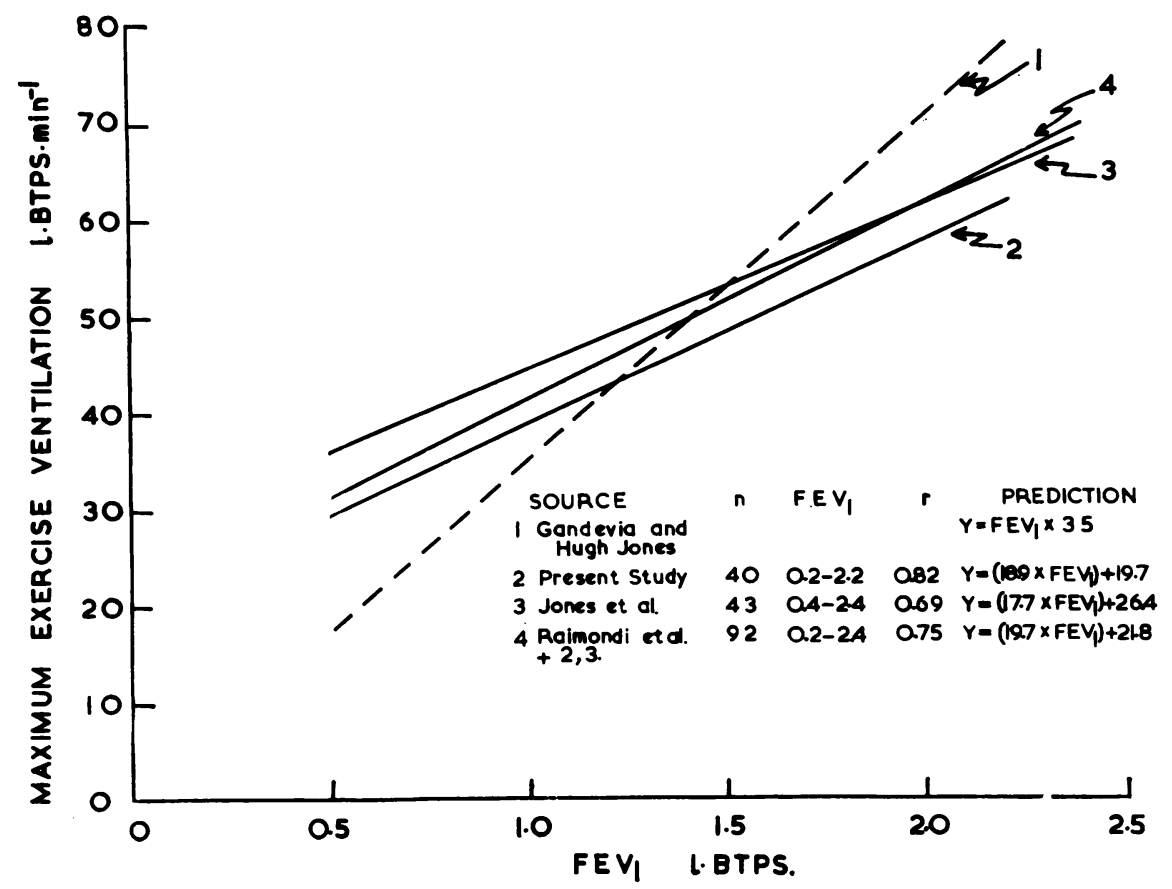

FIG. 5. Summary of different predictors of maximum exercise ventilation in patients with chronic obstructive bronchitis, and the $F E V_{1}$. The solid lines are based on actual values, while the $F E V_{1} \times 35$ (dashed line) considerably underestimates the exercise ventilation in subjects with $F E V_{1}<1 l$.

exercise levels were approached which is associated with a rising blood lactate concentration (Cotes, 1968), and it appears unlikely that the peak blood lactate concentrations were high enough to influence their exercise tolerance. Hence we found no evidence that factors other than the maximum exercise ventilation were playing an important rôle in limiting exercise. The only useful information obtained during the final minute of exercise was the level of maximum ventilation, which we have used to calculate an equation for predicting maximum ventilation from the resting $F E_{1}$. We conclude that abnormalities in the cardiac and ventilatory response to exercise in these patients can be detected readily at low levels of $\mathrm{O}_{2}$ uptake. For most purposes the stress of maximum exercise in patients with chronic obstructive bronchitis appears to be unnecessary since the essential information can be obtained by sub-maximal testing.

We are grateful to the subjects for volunteering to take part in the study. The Tobacco Research Council provided generous support for the Bronchitis Clinic and the Medical Research Council also gave financial support.
R.H.T.E. is indebted to the Wellcome Trust and H.L.H. was in receipt of a British Council Scholarship.

Full details of the individual data are available from S. G. Spiro.

\section{REFERENCES}

Armstrong, B. W., Workman, J. N., Hurt, H. H. Jr., and Roemich, W. R. (1966). Clinico-physiologic evaluation of physical working capacity in persons with pulmonary disease. American Review of Respiratory Diseases, 93, 90.

Astrand, I. (1958). The physical work capacity of workers 50-64 years old. Acta Physiologica Scandinavica, 42, 73.

- (1960). Aerobic work capacity in men and women with special reference to age. Acta Physiologica Scandinavica, 49, Supplement 169.

Astrand, P.-O. (1952). Experimental Studies of Physical Working Capacity in Relation to Sex and Age. Munksgaard, Copenhagen.

— and Rodahl, K. (1970). Textbook of Work Physiology, pp. 165. McGraw-Hill, New York.

Baum, G. L., Schwartz, A., Llamas, R., and Castillo, C. (1971). Left ventricular function in chronic obstructive lung disease. New England Journal of Medicine, 285, 361.

Becklake, M. R., Frank, H., Dagenais, G. R., Ostiguy, G. L., and Guzman, C. A. (1965). Influence of age 
and sex on exercise cardiac output. Journal of Applied Physiology, 20, 938.

Clark, T. J. H., Freedman, S., Campbell, E. J. M., and Winn, R. R. (1969). The ventilatory capacity of patients with chronic airways obstruction. Clinical Science, 36, 307.

Cotes, J. E. (1968). Lung Function. Assessment and Application in Medicine, 2nd edition, pp. 356 and 374. Blackwell Scientific Publications, Oxford.

—, Davies, C. T. M., Edholm, O. G., Healy, M. J. R., and Tanner, J. M. (1969). Factors relating to the aerobic capacity of 46 healthy British males and females, aged 18 to 28 years. Proceedings of the Royal Society, Series B, Biological Sciences, 174, 91.

Davies, C. T. M. (1968). Limitations to the prediction of maximum oxygen intake from cardiac frequency measurements. Journal of Applied Physiology, 24, 700.

- (1972). The oxygen-transporting system in relation to age. Clinical Science, 42, 1.

DuBois, A. B., Botelho, S. Y., Bedell, G. N., Marshall, R., and Comroe, J. H. Jr. (1956). A rapid plethysmographic method for measuring thoracic gas volume: A comparison with a nitrogen washout method for measuring functional residual capacity in normal subjects. Journal of Clinical Investigation, 35, 322.

,-- , and Comroe, J. H. Jr. (1956). A new method for measuring airway resistance in man using a body plethysmograph: Values in normal subjects and in patients with respiratory disease. Journal of Clinical Investigation, 35, 327.

Durnin, J. V. G. A. and Rahaman, M. M. (1967). The assessment of the amount of fat in the human body from measurements of skinfold thickness. British Journal of Nutrition, 21, 681.

Freedman, S. (1970). Sustained maximum voluntary ventilation. Respiration Physiology, 8, 230.

Gabriel, S. K. (1973). Respiratory and circulatory investigations in obstructive and restrictive lung diseases. Acta Medica Scandinavica, Supplement 546.

Gandevia, B. and Hugh-Jones, P. (1957). Terminology for measurements of ventilatory capacity. Thorax, 12, 290.

Godfrey, S. (1970). Manipulation of the indirect Fick principle by a digital computer program for the calculation of exercise physiology results. Respiration, 27, 513.

Wozniak, E. R., Courtenay-Evans, R. J., and Samuels, C. S. (1971). Ear lobe blood samples for blood gas analysis at rest and during exercise. British Journal of Diseases of the Chest, 65, 58 .

Granath, A., Jonsson, B., and Strandell, T. (1964). Circulation in healthy old men, studied by right heart catheterization at rest and during exercise in supine and sitting position. Acta Medica Scandinavica, 176, 425.

Harris, E. A., Kenyon, A. M., Nisbet, H. D., Seelye, E. R., and Whitlock, R. M. L. (1974). The normal alveolar-arterial oxygen-tension gradient in man. Clinical Science and Molecular Medicine, 46, 89.

Hey, E. N., Lloyd, B. B., Cunningham, D. J. C., Jukes, M. G. M., and Bolton, D. P. G. (1966). Effects of various respiratory stimuli on the depth and frequency of breathing in man. Respiration Physiology, 1, 193.
Higgs, B. E., Clode, M., McHardy, G. J. R., Jones, N. L and Campbell, E. J. M (1967). Changes in ventila? tion, gas exchange and circulation during exercise in normal subjects. Clinical Science, 32, 329.

Hohorst, H. J. (1957). Enzymatische bestimmung von 面 (+)Milch Säure. Biochemische Zeitschrift, 328, 509. ำ

Jones, N. L., Campbell, E. J. M., McHardy, G. J. R., Higgs, B. E., and Clode, M. (1967). The estimatio of carbon dioxide pressure of mixed venous blood. during exercise. Clinical Science, 32, 311.

, Jones, G., and Edwards, R. H. T. (1971). Exercise tolerance in chronic airways obstruction. America就 Review of Respiratory Disease, 103, 477.

Levine, G., Housley, E., MacLeod, P., and Macklem, P. T. (1970). Gas exchange abnormalities in mila bronchitis and asymptomatic asthma. New England Journal of Medicine, 282, 1277.

Marcus, J. H., McLean, R. L., Duffell, G. M., and Ingram, R. H. Jr. (1970). Exercise performance in relation to the pathophysiologic type of chronis obstructive pulmonary disease. American Journal Medicine, 49, 14.

McDermott, M., McDermott, T. J., and Collins, M. Mto (1968). A portable bellows spirometer and timing unit for the measurement of respiratory function? Medical and Biological Engineering, 6, 291.

Medical Research Council (1965). Definition and classiff cation of chronic bronchitis for clinical and epide mological purposes. Lancet 1, 775 .

Mellemgaard, K. (1966). The alveolar-arterial oxygen difference: its size and components in normal man? Acta Physiologica Scandinavica, 67, 10.

Ogilvie, C. M., Forster, R. E., Blakemore, W. S., an Morton, J. W. (1957). A standardized breathholding technique for the clinical measurement of the diffuss ing capacity of the lung for carbon monoxide Journal of Clinical Investigation, 36, 1.

Raimondi, A. C., Edwards, R. H. T., Denison, D. M\% Leaver, D. G., Spencer, R. G., and Siddorn, J. A. (1970). Exercise tolerance breathing a low densit gas mixture, $35 \%$ oxygen and air in patients wit chronic obstructive bronchitis. Clinical Science, 38 675.

Reeves, J. T., Grover, R. F., Blount, S. G., and Fillesg G. F. (1961). Cardiac output response to standing and treadmill walking. Journal of Applied Physiolog 16, 283.

Robinson, S. (1938). Experimental studies of physicaf fitness in relation to age. Arbeitsphysiologie, 10, 251 .

Shephard, R. J., Allen, C., Benade, A. J. S., Davie C. T. M., Di Prampero, P. E., Hedman, R., Merrimaa J. E., Myhre, K., and Simmons, R. (1968). The maximum oxygen intake. An international reference standard of cardio-respiratory fitness. Bulletin the World Health Organisation, 38, 757.

Simonsson, B. G., Malmberg, R., and Berglund, E. (1969) Pulmonary gas exchange at rest and during exercise in chronic bronchitis. Scandinavian Journal of Respiratory Disease, 50, 245.

Spiro, S. G. (1975). Cardiorespiratory adaptations t\& exercise in patients with chronic obstructive bronchitis. M.D. Thesis, Manchester University. 
Juniper, E., Bowman, P., and Edwards, R. H. T. (1974). An increasing work rate test for assessing the physiological strain of submaximal exercise. Clinical Science and Molecular Medicine, 46, 191.

Strandell, T. (1964). Heart rate and work load at maximal working intensity in old men. Acta Medica Scandinavica, 176, 301.

van Ganse, W. F., Ferris, B. G. Jr., and Cotes, J. E. (1972). Cigarette smoking and pulmonary diffusing capacity (Transfer factor). American Review of Respiratory Disease, 105, 30.

Requests for reprints to: Dr. R. H. T. Edwards, Department of Medicine, Royal Postgraduate Medical School, Hammersmith Hospital, Du Cane Road, London W12 0HS. 